\title{
Awareness of dehydration state and fluid intake practice among adults population in the Jazan Region of Saudi Arabia, 2019
}

\author{
Osama B. Albasheer ${ }^{1}$ (1), Abdullah Hakami ${ }^{2}$, Abdullah A. Al Faqih ${ }^{2}$, Ibrahim Akkam², Safwan \\ K. Soraihy ${ }^{2}$, Ahmad Mathary ${ }^{2}$, Ali A. Alharbi ${ }^{2}$, Mohammed Yaqoub ${ }^{2}$ and Majed A. Alotayfi ${ }^{2}$ \\ ${ }^{1}$ Department of Family and Community Medicine, Faculty of Medicine, Jazan University, Jazan, Kingdom of Saudi Arabia \\ ${ }^{2}$ Faculty of Medicine, Jazan University, Jazan, Kingdom of Saudi Arabia
}

(Received 10 May 2021 - Final revision received 31 August 2021 - Accepted 8 September 2021)

Journal of Nutritional Science (2021), vol. 10, e84, page 1 of 7

doi: $10.1017 /$ jns.2021.81

Abstract

Despite the hot climate and high humidity in the Jazan Region of Saudi Arabia, which increases risk for dehydration, no previous studies have assessed awareness of dehydration and fluid intake practice among adults in this region. Therefore, the aim of this cross-sectional study was to determine awareness of the dehydration state and fluid intake practices among 440 adults in the Jazan Region of Saudi Arabia. Out of the total, $51 \cdot 8 \%$ were male and $48 \cdot 2 \%$ were females. Good knowledge of dehydration definition and prevention and recommended minimum water intake was observed in 98,95 and $75 \%$ of the participants, respectively. Fifty-nine percent of the participants met the minimum daily requirement of 31 or more per day. The age $(95 \%$ CI 1.003 , $1 \cdot 017$, $P$ value $=0.006)$, diabetes $(95 \%$ CI $1.028,1.459, P$ value $=0.023)$ and prior hospitalisation due to dehydration $(95 \% \mathrm{CI} 1 \cdot 010,1 \cdot 378, P$ value $=0 \cdot 037)$ were associated with higher water intake. Additional glasses of coffee (95\% CI 1.02, 1.115, $P$ value $=0 \cdot 004)$ and juice $(95 \% \mathrm{CI} 1 \cdot 039,1 \cdot 098, P$ value $<0 \cdot 001)$ were associated with more water intake. The participants exhibited good knowledge of dehydration definition, symptoms and consequences. Intake of fluids such as 'juice and coffee' enhances more water intake. Although two-thirds of the participants met the recommended daily water intake, still one-third of them did not meet this level. Innovative approaches to enhance healthy drinking are warranted and may include partnering with patients to take an active role in hydration monitoring and increasing communication with the different healthcare providers.

Keywords: Dehydration state: Dry skin: Prevention: Renal stones: Thirst: Water intake

\section{Introduction}

Water plays a fundamental role in the biological structure and function of all living cells ${ }^{(1)}$. Water regulates body temperature, protects body organs and tissues, helps dissolve minerals and nutrients to make them accessible and helps regulate acid-base balance. In a healthy adult, with an average $70 \mathrm{~kg}$, water accounts for $60 \%$ of body weight and the body requires 2-3.5 1 per day of total water intake ${ }^{(2)}$. Water inputs composed of three major sources: major one result when drinking water and liquid with high water contents, second the water we eat come various food with a large amount of water content and the third source produce from the oxidation of macronutrients (endogenous or metabolic water) ${ }^{(3)}$. A person is considered dehydrated if they lose as little as $3 \%$ of their body weight from water depletion ${ }^{(2)}$. Insufficient water intake with loss of body mass is associated with poor memory and $\operatorname{attention}^{(4)}$.

Imbalance between water intake and loss causes a state of dehydration, which is associated with morbidity and mortality particularly in older adults ${ }^{(5,6)}$. The risk of developing constipation, dental carries urinary tract infections and renal stones increases due to dehydration ${ }^{(7,8)}$. The prevalence of dehydration varies with age (16-21\%) and the signs and symptoms include thirst, mouth dryness, decrease in urination or darkening of urine. Rapid weight loss (over $10 \%$ of body weight) is considered as severe dehydration ${ }^{(9)}$.

* Corresponding author: Osama B. Albasheer, email drosama802@gmail.com 
Awareness of dehydration and fluid intake was found unsatisfactory in cross-sectional surveys among adults in thirteen countries worldwide ${ }^{(10)}$. A study done in China revealed that $28.4 \%$ of people under the study were unaware of minimum daily water intake and $48 \cdot 3 \%$ drink water only when they feel thirsty $^{(11)}$. Another study done in Australia reported that $82 \%$ of the population failed to achieve adequate daily water intake ${ }^{(12)}$.

Public awareness of dehydration is not widely assessed in Saudi Arabia. A previous study among people living in Riyadh, Saudi Arabia, to assess awareness of dehydration and fluid intake, displayed good participants' knowledge of the common symptoms of dehydration, however knowledge was lacking for uncommon symptoms and serious consequences of dehydration ${ }^{(13)}$. Awareness of dehydration and fluid intake in other areas of Saudi Arabia, particularly those with climates that are conducive to dehydration, are needed.

Jazan Region is a subtropical and coastal area that is known of having hot climate and high temperature and humidity for most of the year, with a lack of natural thermal springs, which gets people dehydrated easily. Therefore, the aim of the present study was to determine the knowledge of dehydration state and fluid intake practice among adults of the Saudi Arabian population in the Jazan Region.

\section{Methods}

\section{Study setting}

The present study was conducted among adults living in the Jazan Region. Jazan is the capital of Jazan Region. It is located in the southwest corner of Saudi Arabia and the estimated population, in 2017, was 1.6 million $^{(14)}$.

\section{Ethics approval and consent to participate}

Bioethics standards of the Kingdom of Saudi Arabia were considered while conducting this study. Participants were informed that they had the right to withdraw from the study at any time, their information would be kept anonymous and the data collected would only be used for scientific purposes. Written informed consent was obtained from each participant after explaining the purpose of the study. Also, permission was obtained from the administration of all colleges participated in the study before data collection. Finally, ethical approval for this study was provided by the Standing Committee for Scientific Research Ethics-Jazan University (Ref. no: REC41/6/154).

\section{Study design and population}

A cross-sectional, descriptive, study was conducted to gather information related to the awareness of dehydration and fluid intake among adults living in the Jazan Region of Saudi Arabia.

A multi-stage random sampling method was used for conducting this study. A total of 440 participants were enrolled using the Epi Info program formula, used for sample size calculation. Given the unavailability of previous studies in the Jazan Region, we assumed that $50 \%$ of the population were aware of dehydration status. Therefore, calculation of the sample size was managed on the presumption that the nonresponse rate of $10 \%$, the confidence level (95\%), the margin of error not more than $(5 \%)$ and the total awareness of $(50$ $\%$ ). The value of $95 \%$ CI from the normal distribution is 1.96 and for practical reasons we rounded it to be 2 , so the estimated sample size increased to 440 participants. There were 179 primary health care (PHC) centres in the region distributed into three subregions (mountain, land and coast). Three PHC centres from each subregion were selected for acquiring the sample. Participants were recruited while visiting the selected PHC centres. Face-to-face interviews were conducted via trained medical students.

\section{Inclusion criteria}

All adult citizens (age $\geq 18$ years) residing in the Jazan Region of Saudi Arabia of both sexes and who had agreed to participate were included and considered appropriate for the study.

\section{Exclusion criteria}

Citizens $<18$ years and unwilling to participate were excluded. Those extremely ill or unable to communicate were also excluded from the study.

\section{Data collection tools}

Given the unavailability of a standard questionnaire, the authors in a previous study conducted in Riyadh of Saudi Arabia in 2014, developed a self-reported questionnaire to focus on awareness of dehydration definition, symptoms, causes, prevention, water intake recommendation and fluid intake practices ${ }^{(13)}$. The questionnaire was drafted in English and translated into Arabic and back-translated to validate the accuracy of the translation prior to validation. The final questionnaire was distributed to 393 participants and their results were published in 2018. Permission for use was taken from the authors and Arabic version was received. The first page of the questionnaire comprised clear information about the study's objectives and clarified information about participation, confidentiality, withdrawal and informed consent. The questionnaire consisted of twenty-six questions and comprised four primary sections: the first gathered information on the respondents' socio-demographic and disease characteristics, including age, sex, nationality, education level, work status, monthly income, history of chronic diseases and health-related behaviours; the second assessed the participants' knowledge of dehydration, including definition, clinical symptoms, consequences and treatment; the third section considered information about recommended daily water intake and the fourth sections assessed preventive measures taken to avoid dehydration.

The knowledge of dehydration symptoms, causes and consequences were based on dichotomy 'yes' and 'no' questions. Dehydration definition was assessed based on three options (I'll be dehydrated if I don't drink enough fluid, I'll be dehydrated if I don't eat properly and I'll be dehydrated if I don't have enough sleep). Knowledge was considered good 
when the participants selected the first or the second or all three options and considered poor when 'no' was selected the first option.

Dehydration prevention was assessed based on three preferences (dehydration risk can be reduced if I drink enough fluid, by consuming food with high water content, in hot weather fluid replenishment as priority). Good knowledge of dehydration preventions was considered when all or two preferences were selected 'yes'. Knowledge was considered poor when the first preference was considered 'no'.

The total water intake was assessed based on the number of water glasses used per day. Good knowledge of daily water intake recommendations was considered when the participants selected 2 or 31 out of options.

\section{Data presentation and statistical analysis}

The survey data were analysed using Statistical Package for the Social Sciences (SPSS) version 25. Frequencies and percentages were used for analysing the selected socio-demographic data. Poisson regression was used to determine the predictors of water cups consumptions, the scale parameter was set to Pearson $\chi^{2}$ to make the model fit the over dispersion in data. An independent $T$-test was used to check if there is a significant difference in the total fluid intake between hospitalised due to dehydration and those who were not. Results were reported as a $95 \%$ confidence interval, a rate ratio and a $P$ value. A $P$ value less than 0.05 was used as the cut-off level for statistical significance.

\section{Results}

\section{Socio-demographic and disease characteristics}

A total of 440 participants filled the survey, $228(51.82 \%)$ were male, $212(48.18 \%)$ were female and the mean age of participants was $32 \cdot 19+10 \cdot 17$ (Table 1). Out of the total, $406(92.27 \%)$ were Saudi. The mean BMI of participants was $25 \cdot 28+5 \cdot 29$. Of the participants, $249(56.59 \%)$ had received higher education and $144(32.70 \%)$ were professionals. With regard to health and health-related behaviours, $56(12.70 \%)$ reported diabetes, $42(9.50 \%)$ reported hypertension and $82(18 \cdot 60 \%)$ were smokers (Table 1$)$.

\section{Knowledge of dehydration definition, prevention, consequences and water intake recommendation}

Good knowledge of dehydration definition, dehydration prevention and recommended minimum water intake was observed in $431(97 \cdot 95 \%), 417(94 \cdot 8 \%)$ and $330(75 \%)$ of the participants, respectively (Table 2). Regarding dehydration consequences, 331 $(75.2 \%)$ reported that severe dehydration can could to kidney renal stones, $113(25.7 \%)$ reported that severe dehydration could lead to brain damage and $76(17.3 \%)$ reported that severe dehydration could lead to seizers.

\section{Commonly reported causes of dehydration}

The commonly reported causes of dehydration were diarrhoea (73.4\%), sweating (52.05) and vomiting (51.82). Fever (39.8 $\%$ ), increased urination $(35.9 \%)$ and flight travel $(15.9 \%)$ were less reported causes of dehydration (Fig. 1).
Table 1. Socio-demographic and diseases profiles of the participants $(n=440)$

\begin{tabular}{|c|c|c|}
\hline Demographic & Number $(N)$ & Percentage (\%) \\
\hline Age (mean, sD) & $32 \cdot 19$ & $10 \cdot 17$ \\
\hline BMI (mean, sD) & $25 \cdot 28$ & $5 \cdot 29$ \\
\hline \multicolumn{3}{|l|}{ Gender $(n, \%)$} \\
\hline Male & 228 & $51 \cdot 82$ \\
\hline Female & 212 & $48 \cdot 18$ \\
\hline \multicolumn{3}{|l|}{ Nationality $(n, \%)$} \\
\hline Saudi & 406 & $92 \cdot 27$ \\
\hline Non-Saudi & 34 & 7.73 \\
\hline \multicolumn{3}{|l|}{ Educational level } \\
\hline Primary & 17 & $3 \cdot 86$ \\
\hline Secondary & 27 & $6 \cdot 14$ \\
\hline Diploma & 147 & 33.41 \\
\hline University & 249 & $56 \cdot 59$ \\
\hline \multicolumn{3}{|l|}{ Occupation $(n, \%)$} \\
\hline Professionals & 206 & $46 \cdot 8$ \\
\hline Workers & 86 & 19.5 \\
\hline Housewives & 60 & $13 \cdot 6$ \\
\hline Students & 76 & $17 \cdot 3$ \\
\hline \multicolumn{3}{|c|}{ Monthly income SR $(n, \%)$} \\
\hline$<3000$ & 199 & $45 \cdot 2$ \\
\hline $3000-4900$ & 53 & 12 \\
\hline 5000-8999 & 63 & $14 \cdot 3$ \\
\hline $9000-14999$ & 93 & $21 \cdot 1$ \\
\hline$>15000$ & 32 & $7 \cdot 3$ \\
\hline \multicolumn{3}{|c|}{ Reported chronic diseases } \\
\hline Diabetes & 56 & $12 \cdot 7$ \\
\hline Hypertension & 42 & 9.5 \\
\hline Heart diseases & 9 & $2 \cdot 0$ \\
\hline Kidney diseases & 25 & 5.7 \\
\hline \multicolumn{3}{|c|}{ Health-related behaviours } \\
\hline Smoking & 82 & $18 \cdot 6$ \\
\hline Khat chewing & 46 & 10.5 \\
\hline
\end{tabular}

Commonly reported factors that affect restoring fluid loss

Hot climate exposure $(59 \cdot 3 \%)$, diarrhoea $(44.3 \%)$ and exercise $(43.2 \%)$ were the commonly reported factors to affect restoring fluid loss (Fig. 2).

\section{Commonly reported symptoms of dehydration}

Thirst $(83.9 \%)$, dry lips $(82.5 \%)$ and dry skin $(55.5 \%)$ were the most frequently reported symptoms, while dizziness $(33.6$ $\%$ ), lightheadedness $(27.5 \%)$ and muscle cramps $(17.5 \%)$ were the less frequently reported symptoms (Fig. 3).

\section{Predictors of water intake}

More water intake was observed by increment in age, being diabetic and with prior hospitalisation due to dehydration $(P$ value $=0.006,0.023$ and 0.037 , respectively). The participants were reported more water intake with intake of additional glasses of coffee $(P$ value $=0.004)$ and juice $(P$ value $<0 \cdot 001)$. More water intake was not significantly affected by gender differences, educational level and BMI status $(P$ value $=0.24,0.278$ and 0.142 , respectively; Table 3$)$.

\section{Discussion}

The aim of the present study was to determine the awareness of dehydration state and fluid intake practice in the Jazan 
Table 2. Knowledge of dehydration definition, prevention, consequences and water intake recommendation

\begin{tabular}{|c|c|c|}
\hline Question & Selected $(n / \%)$ & Not Selected $(n / \%)$ \\
\hline \multicolumn{3}{|l|}{ Knowledge of dehydration definition } \\
\hline I can become dehydrated if I don't drink enough fluids & $410(93.2 \%)$ & $30(6 \cdot 8 \%)$ \\
\hline I can become dehydrated if I don't eat properly & $21(4 \cdot 80 \%)$ & 419 (95.2\%) \\
\hline I can become dehydrated if I don't get enough sleep & $8(1.81 \%)$ & $432(98.19 \%)$ \\
\hline I don't know & $1(0.23 \%)$ & $439(99.77 \%)$ \\
\hline \multirow[t]{2}{*}{ Overall knowledge } & Good & Poor \\
\hline & $431(97.95 \%)$ & $9(2.05 \%)$ \\
\hline \multicolumn{3}{|l|}{ Knowledge of dehydration prevention } \\
\hline By drinking enough fluids (water/milk/juice/tea) & $417(94.8 \%)$ & $23(5 \cdot 2 \%)$ \\
\hline By consuming foods with high water content (e.g. watermelon, oranges, apples, etc.) & $355(80.68 \%)$ & $85(19.31 \%)$ \\
\hline In hot climate, replenish fluids as priority & $355(80.68 \%)$ & $85(19.31 \%)$ \\
\hline \multirow[t]{2}{*}{ Overall knowledge } & Good & Poor \\
\hline & $417(94.8 \%)$ & $23(5 \cdot 2 \%)$ \\
\hline \multicolumn{3}{|l|}{ Knowledge of dehydration consequences } \\
\hline Kidney stones & $331(75 \cdot 2 \%)$ & $109(24.8 \%)$ \\
\hline Death & $177(40 \cdot 2 \%)$ & $263(59.8 \%)$ \\
\hline Brain damage & $113(25.7 \%)$ & $327(74.3 \%)$ \\
\hline Seizure & $76(17 \cdot 3 \%)$ & $364(82.7 \%)$ \\
\hline \multicolumn{3}{|l|}{ Knowledge of water intake recommendation } \\
\hline 11 & $41(9 \cdot 3 \%)$ & $399(90 \cdot 7 \%)$ \\
\hline 21 & $133(30 \cdot 2 \%)$ & 307 (69.8 \%) \\
\hline 31 & $197(44 \cdot 8 \%)$ & $243(55 \cdot 2 \%)$ \\
\hline 41 & $69(15.7 \%)$ & $371(84.3 \%)$ \\
\hline \multirow[t]{2}{*}{ Overall knowledge } & Good & Poor \\
\hline & $330(75 \%)$ & $110(25 \%)$ \\
\hline
\end{tabular}

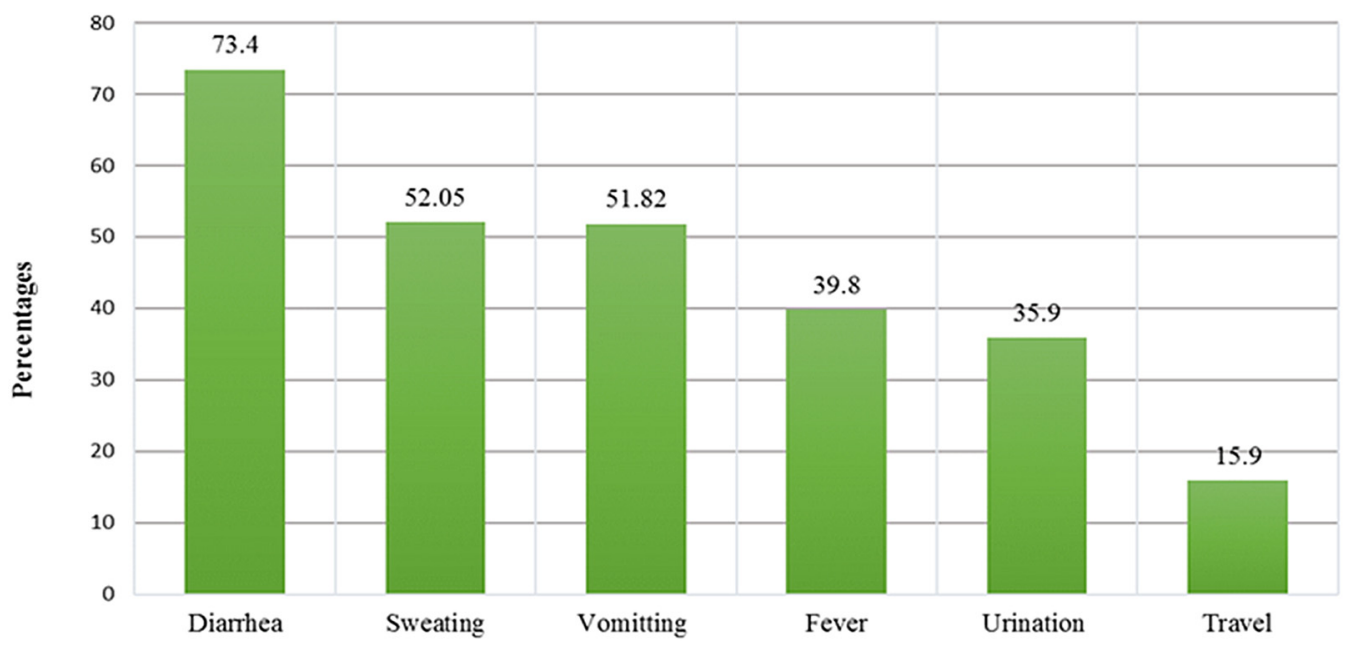

Fig. 1. Reported dehydration causes.

Region of Saudi Arabia. Poor awareness of dehydration and fluid intake was reported in different countries worldwide $^{(10,11)}$. Nearly, $50 \%$ of the adult population fail to run across the recommended total water intake despite the adverse health outcomes associated with chronic low fluid intake ${ }^{(15)}$. The participants in the present study reported good knowledge of dehydration definition and fluid intake practice. One-third of them did not meet the required minimum water intake and they have poor knowledge of dehydration consequences and some of dehydration symptoms. Focus education directed to the dehydration symptoms and complications will help to improve the overall hydration state.

Though the participants showed good knowledge levels with regard to the common symptoms of dehydration like excessive thirst, dry lips and dry skin and were able to elicit the common causes of dehydration like diarrhoea, sweating and vomiting, their knowledge regarding headache, dizziness and muscle cramps, as symptoms and fever and excessive urination, as causes of dehydration were poor. These variations in knowledge assessment were similar to the results of the crosssectional survey of knowledge assessment of dehydration among people living in Riyadh City during summer ${ }^{(13)}$.

In the present study, the participants were aware of drinking water, as almost two-thirds of them agreed to drink 31 or per day, which is consistent with institute of medicine (IOM) guidelines and with the results of a survey conducted among school students in China ${ }^{(16)}$. Based on the recommendations of IOM, water intake of $\geq 3.71$ daily was considered adequate 


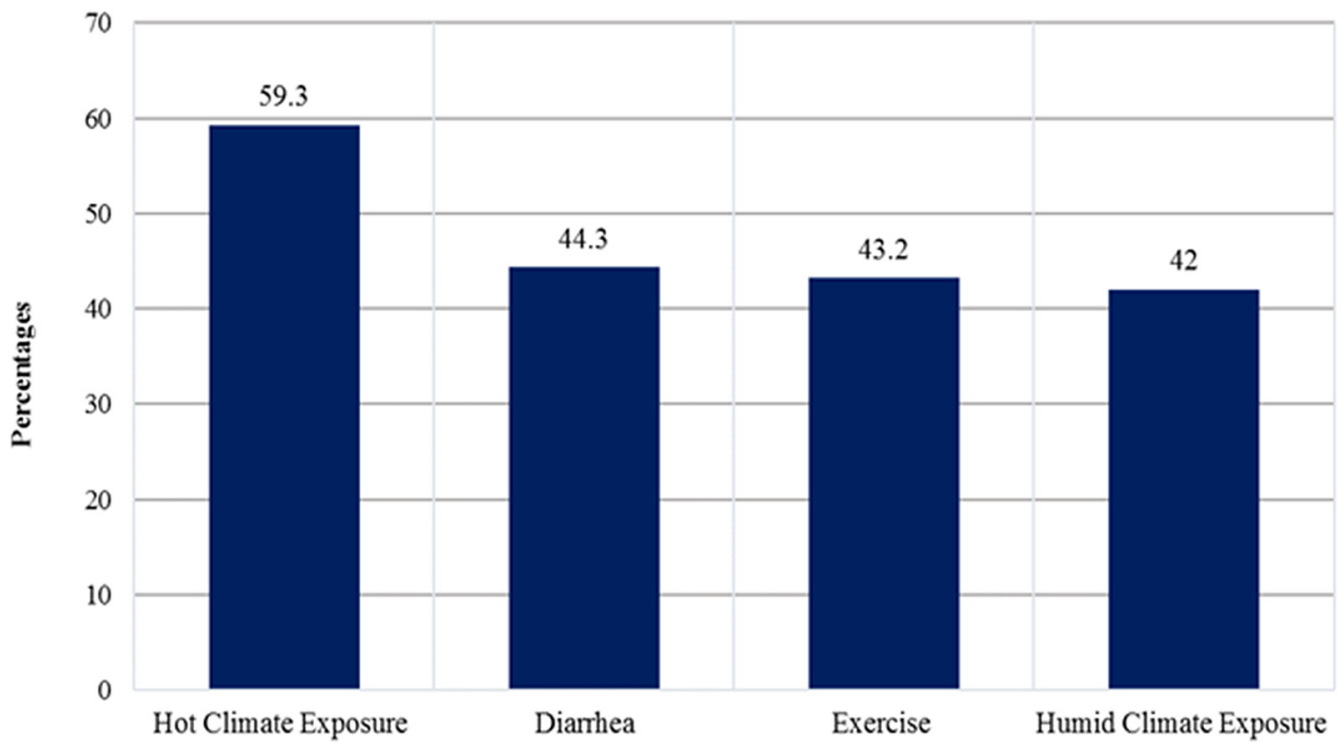

Fig. 2. Reported factors that affect restoring fluid loss.

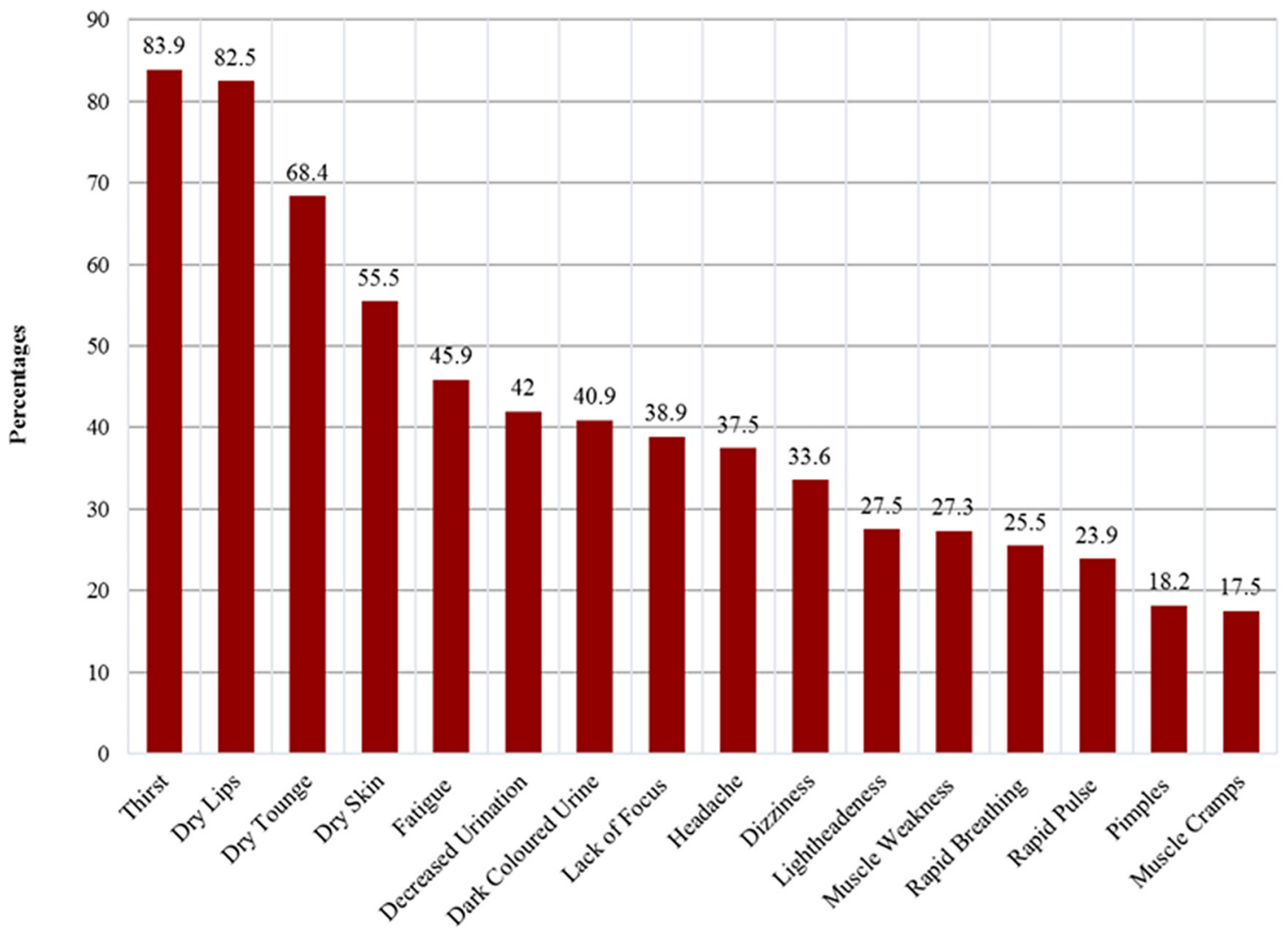

Fig. 3. Reported symptoms of dehydration.

for men and $\geq 2 \cdot 71$ daily was considered adequate for women ${ }^{(17)}$. In the arid climate, more water intake is needed and 4.1-6.0 lis the minimum recommended daily intake for a healthy, $70 \mathrm{~kg}$ adult ${ }^{(18)}$. Good awareness of water intake consistent with good knowledge regarding dehydration definition was similarly reported by Shaheen et al. in Saudi Arabia ${ }^{(13)}$. Adequate water intake is very important in hot climate and in sport. To prevent dehydration, water intake should be replenished regularly ${ }^{(19)}$.
Regarding knowledge of dehydration consequences, threefourth of the participants in the present study reported that severe dehydration could lead to the development of renal stones. However, less than one-third of the participants agreed that severe dehydration could lead to seizures, brain damage and even death. The risk of developing renal stones and urinary tract infections due to dehydration is well observed in the literature $^{(20-22)}$. The impact of chronic dehydration could 
Table 3. Predictors of water intake

\begin{tabular}{|c|c|c|c|}
\hline Predictors & Incidence Rate Ratio & $95 \%$ confidence limits & $P$ value* \\
\hline Intercept & $1 \cdot 376$ & $1 \cdot 025,1.846$ & $0.034^{*}$ \\
\hline Age & $1 \cdot 01$ & $1.003,1.017$ & $0.006^{*}$ \\
\hline Gender (Male $v$. Female) & 0.24 & $0.950,1.227$ & 0.24 \\
\hline BMI Category (Normal v. Obese) & $1 \cdot 141$ & $0.957,1.360$ & 0.142 \\
\hline BMI Category (Overweight $v$. Obese) & $1 \cdot 101$ & $0.831,1.458$ & 0.504 \\
\hline BMI Category (Underweight $v$. Obese) & 1.005 & $0.840,1.204$ & 0.953 \\
\hline Education Level (Primary $v$. University) & 0.836 & $0.604,1.156$ & 0.278 \\
\hline Education Level (Diploma $v$. University) & $1 \cdot 128$ & $0.884,1.439$ & 0.332 \\
\hline Education Level (Secondary $v$. University) & 0.987 & $0.865,1.126$ & 0.848 \\
\hline History of diabetes mellitus (Yes $v$. No) & $1 \cdot 225$ & $1.028,1.459$ & $0.023^{*}$ \\
\hline History of Hypertension (Yes v. No) & 1.007 & $0.815,1.244$ & 0.949 \\
\hline History of Heart Disease (Yes v. No) & 0.637 & $0.387,1.047$ & 0.075 \\
\hline History of Kidney Disease (Yes $v$. No) & 1.093 & $0.854,1.398$ & 0.48 \\
\hline History of Hospitalisation due to Dehydration (Yes $v$. No) & $1 \cdot 18$ & $1 \cdot 010,1 \cdot 378$ & $0.037^{*}$ \\
\hline Coffee Intake & 1.067 & $1 \cdot 02,1 \cdot 115$ & $0.004^{*}$ \\
\hline Juice Intake & 1.068 & $1.039,1.098$ & $<0.001^{*}$ \\
\hline Tea Intake & 1.005 & $0.966,1.047$ & 0.793 \\
\hline Soda Intake & 0.956 & $0.912,1.002$ & 0.059 \\
\hline
\end{tabular}

${ }^{*} P$ value is based on the Poisson regression model (less than 0.05 was used as the cut-off level for statistical significance).

extent to chronic kidney diseases (CKD) especially in the present of co-morbid diseases and extreme hot climate ${ }^{(23)}$. Limited knowledge of dehydration consequences were reported by Zuo et al., in China, and Shaheen et al., in Saudi Arabia $^{(11,13)}$. The impact of severe dehydration on brain functioning has been well established in the literature, particularly in elderly adults and young children ${ }^{(24-27)}$. Even mild dehydration has been linked to significant effects on everyday functioning ${ }^{(28)}$. Thus the beneficial hydration effect was not only observed for speed of cognitive functioning but also for processing of everyday functioning.

Regarding the predictors of water intake, increment in age, coffee intake and juice intake were associated with more water intake. Similarly, juice intake has been reported as a predictor of water intake by Shaheen et al. ${ }^{(13)}$, while coffee intake has been reported as a predictor of water intake by Christopher among university students ${ }^{(29)}$.

Theoretically, when the people were well educated, their knowledge of dehydration is expected to be increased and their intake of hydration recommendations will be better than less educated people. However, in the present study, although the majority of the participants received high education, we did not find a significant correlation between hydration knowledge and the level of education. Same finding was reported by Shaheen et al., in Riyadh City. Large sample size cross-sectional and more qualitative studies are needed to test this correlation.

Weight status has not been associated with more water intake in this study, while it was reported as a predictor of more water intake in the literature ${ }^{(13,30)}$. In contrast to the present study, Shaheen et al. and Goodman et al. had reported participants aged 55 years and above drink less compared with the younger group. Additional glass of tea was not found to be linked with more water intake, while it was reported as a predictor of more water intake by Shaheen $e t$ al. Being diabetic and prior history of hospitalisation were found to be linked with more water intake in the present study, while contradicting responses were observed by others ${ }^{(13,30)}$. These variations in the predictors of water intake could be explained by human nature and different perceptions. Variation in sample size and assessment technique could also explain disparities in the predictors of water intake in different populations.

The results of the present study provide fresh knowledge and reflect the state of water intake in the Jazan Region. The sample was taken from the randomly selected PHC centres, which nearly represented the population under the study. However, being cross sectional will limit the generalisation of the results. A small sample size is also one of the limitations. A large sample size study will help to test the correlation between the different predictors and water intake practice.

\section{Conclusion}

The participants exhibited good knowledge of dehydration definition and recommended minimum water intake. However, the knowledge was lacking for the less common symptoms, causes, and of potentially serious consequences of dehydration. Intake of fluids such as 'juice and coffee' enhances more water intake. Although two-thirds of the participants met the recommended daily water intake, still one-third of them did not meet this level.

Innovative approaches to enhance healthy drinking are warranted and may include partnering with patients to take an active role in hydration monitoring and increasing communication with the different healthcare providers.

\section{Acknowledgements}

Great thanks were expressed for the participation in this study and the leaders in the primary health care centres for their help and support.

This study is self-funded and we did not received any financial support from any funding agency.

O. A. contributed to study conception and design, statistical analysis, final interpretation of data, and drafting and revising 
of the article and gave final approval. A. H. and M. A. contributed to study design, acquisition, interpretation of data and revision of the article. All authors have critically reviewed and approved the final draft and are responsible for the content and similarity index of the manuscript.

The authors declare that they have no conflict of interest.

\section{References}

1. Bailey SP (1994) Nutrition in Exercise and Sport, 934.

2. Collins M \& Claros E (2011) Recognizing the face of dehydration. Nursing 2020, 22-26.

3. Rani J, Sharma UK \& Sharma DN (2018) Role of adequate water intake in purification of body. Environ Conserv J 19, 183-186.

4. Benton D, Jenkins KT, Watkins HT, et al. (2016) Minor degree of hypohydration adversely influences cognition: a mediator analysis. Am J Clin Nutr 104, 603-612.

5. El-Sharkawy AM, Sahota O \& Lobo DN (2015) Acute and chronic effects of hydration status on health. Nutr Rev 73, 97-109.

6. Popkin BM, D’Anci KE \& Rosenberg IH (2010) Water, hydration and health. Nutr Rev 68, 439-458.

7. Ship JA \& Fischer DJ (1997) The relationship between dehydration and parotid salivary gland function in young and older healthy adults. Biol Sci Med Sci 52, M310-M319.

8. Warren JL, Bacon WE, Harris T, et al. (1994) The burden and outcomes associated with dehydration among US elderly, 1991. Am J Public Health 84, 1265-1269.

9. Gandy J (2015) Water intake: validity of population assessment and recommendations. Eur J Nutr 54, 11-16.

10. Ferreira-Pêgo C, Guelinckx I, Moreno LA, et al. (2015) Total fluid intake and its determinants: cross-sectional surveys among adults in 13 countries worldwide. Eur J Nutr 54, 35-43.

11. Ma G, Zhang Q, Liu A, et al. (2012) Fluid intake of adults in four Chinese cities. Nutr Rev 70, S105-S110.

12. Sui Z, Zheng M, Zhang M, et al. (2016) Water and beverage consumption: analysis of the Australian 2011-2012 National Nutrition and Physical Activity Survey. Nutrients 8, 678.

13. Shaheen NA, Alqahtani AA, Assiri H, et al. (2018) Public knowledge of dehydration and fluid intake practices: variation by participants' characteristics. BMC Public Health 18, 1346.

14. ELyas TB, ELsidig EM, Aseri A, et al. (2016) Knowledge, attitudes and preventive practices of house hold regarding dengue fever in the rural areas of Jazan Region, Saudi Arabia. Int J Prev Med Res $2,8-12$.
15. Belogianni K, Gandy J, van Ginkel A, et al. (2019) European healthy hydration awareness campaign for dietitians. Ann Nutr Metab 74, 57-65.

16. Liu J, Hu X, Zhang Q, et al. (2014) Knowledge, attitude and practice on drinking water of primary and secondary students in Shenzhen. Wei Sheng Yan Jiu 43, 419-422.

17. National Academies of Sciences EA (2005) Dietary Reference Intakes for Water, Potassium, Sodium, Chloride, and Sulfate. Washington, DC: The National Academies Press.

18. Howard G, Bartram J, Water S, et al. (2003) Domestic water quantity, service level and health (No. WHO/SDE/WSH/03.02). World Health Organization.

19. Nuccio RP, Barnes KA, Carter JM, et al. (2017) Fluid balance in team sport athletes and the effect of hypohydration on cognitive, technical, and physical performance. Sport Med 47, 1951-1982.

20. Borghi L, Meschi T, Amato F, et al. (1996) Urinary volume, water and recurrences in idiopathic calcium nephrolithiasis: a 5-year randomized prospective study. J Urol 155, 839-843.

21. Khan SR, Pearle MS, Robertson WG, et al. (2016) Kidney stones. Nat Rev Dis Prim 2, 1-23.

22. Alelign T \& Petros B (2018) Kidney stone disease: an update on current concepts. Adv Urol 2018, 3068365.

23. Siriwardhana EA, Perera PA, Sivakanesan R, et al. (2015) Dehydration and malaria augment the risk of developing chronic kidney disease in Sri Lanka. Indian J Nephrol 25, 146.

24. Pross N (2017) Effects of dehydration on brain functioning: a lifespan perspective. Ann Nutr Metab 70, 30-36.

25. Sfera A, Cummings M \& Osorio C (2016) Dehydration and cognition in geriatrics: a hydromolecular hypothesis. Front Mol Biosci 3, 18.

26. Lešnik A, Piko N, Železnik D, et al. (2017) Dehydration of older patients in institutional care and the home environment. Res Gerontol Nurs 10, 260-266.

27. Whitney RE, Santucci K, Hsiao A, et al. (2016) Cost-effectiveness of point-of-care testing for dehydration in the pediatric ED. Am J Emerg Med 34, 1573-1575.

28. Armstrong LE, Ganio MS, Casa DJ, et al. (2012) Mild dehydration affects mood in healthy young women. J Nutr 142, 382-388.

29. Ekpenyong CE \& Akpan IAM (2017) High prevalence and associated risk factors of dehydration among college students: implications for health and academic performance. Int J Community Med Public Health 4, 1043-1055.

30. Goodman AB, Blanck HM, Sherry B, et al. (2013) Behaviors and attitudes associated with low drinking water intake among US adults, food attitudes and behaviors survey, 2007. Prev Chronic Dis $10,1-10$. 